\title{
La desaparición del silencio positivo de las licencias ambientales ${ }^{1}$
}

\section{The disappearance of the positive silence of environmental licenses}

\author{
Iñigo Sanz Rubiales \\ Universidad de Valladolid (España) \\ isanz@der.uva.es
}

\section{NOTA BIOGRÁFICA}

Doctor en Derecho por la Universidad de Valladolid. Catedrático de Derecho Administrativo. Universidad de Valladolid. Principales líneas de investigación: derecho ambiental, derecho administrativo sancionador.

\begin{abstract}
RESUMEN
La Ley de Procedimiento Administrativo Común de 2015 mantiene la regla general del silencio administrativo positivo, pero incorpora la excepción ambiental, cuando la actividad pueda producir daños al medio ambiente, en cuyo caso el silencio será negativo. Esta previsión debe aplicarse al régimen de licencias de actividad, regulado de forma heterogénea por las diversas Comunidades Autónomas. El Tribunal Constitucional ha confirmado la primacía de esta regulación básica en su sentencia 70/2018.
\end{abstract}

\section{PALABRAS CLAVE}

Silencio administrativo; licencias ambientales; medio ambiente.

\begin{abstract}
The Common Administrative Procedure Act of 2015 maintains the general principle of positive administrative silence, but incorporates the environmental exception, when the activity may cause damage to the environment, in which case the silence will be negative. This forecast must be applied to the regime of environmental licenses, regulated heterogeneously by the different Autonomous Communities. The Constitutional Court has confirmed the primacy of this basic regulation in its judgment 70/2018.
\end{abstract}

\section{KEYWORDS}

Administrative silence; environmental licenses; environment.

\section{SUMARIO}

INTRODUCCIÓN. 1. LAS LICENCIAS AMBIENTALES: DE LA REGULACIÓN ÚNICA A LA MÁXIMA HETEROGENEIDAD POR LA AUSENCIA DE NORMATIVA BÁSICA. 2. EL SILENCIO EN LAS AUTORIZACIONES AMBIENTALES DEBE SER NEGATIVO. 2.1. LA PAULATINA RECEPCIÓN DE ESTA DOCTRINA POR EL LEGISLADOR ESPAÑOL. 2.2. LA JURISPRUDENCIA EUROPEA: EL SILENCIO POSITIVO NO ASEGURA EL CONTROL PÚBLICO AMBIENTAL. 2.3. ALGUNAS PREVISIONES DE DERECHO COMPARADO. LAADMINISTRACIÓN NO PUEDE ABDICAR DE SU RESPONSABILIDAD AMBIENTAL. 2.4. JUSTIFICACIÓN DEL SILENCIO NEGATIVO: EL PAPEL DE LOS PRINCIPIOS DE PROPORCIONALIDAD Y DE PREVENCIÓN. 2.4.1. El principio de proporcionalidad: si no hay posibles daños al ambiente (u otra razón imperiosa de interés general), no cabe exigir autorización. 2.4.2. El principio de prevención: si hay da-

\footnotetext{
1 Este trabajo se enmarca en el proyecto "Fundamentos de una codificación del Derecho Administrativo general básico español",
} DER2015-66525-P (MINECO-FEDER). 
ños posibles al ambiente, el silencio debe ser negativo; así se impide su posible legitimación por pasividad administrativa. 3. LA CONFIRMACIÓN DEL SILENCIO NEGATIVO: LA STC 70/2018, DE 21 DE JULIO Y SUS CONSECUENCIAS PARA EL RÉGIMEN JURÍDICO EN LAS LICENCIAS AMBIENTALES. 3.1. DESAPARICIÓN DEL SILENCIO ESTIMATORIO EN LAS LICENCIAS AMBIENTALES. 3.2. UN AVANCE PARA LA INTERPRETACIÓN CORRECTA DE LA CLÁUSULA «CONTRA LEGEM». CONCLUSIONES.

\section{INTRODUCCIÓN}

Las tradicionales licencias de actividades clasificadas, reguladas otrora en el RAMINP, han sido sustituidas por regímenes autonómicos de licencias ambientales sin un régimen común en cuanto a las actividades sometidas a ellas y en cuanto al sentido del silencio administrativo en el caso de que la Administración local competente no resuelva en plazo.

Por otra parte, la Ley 39/2015, de Procedimiento Administrativo Común, dictada en ejercicio de la competencia exclusiva estatal ex. art. 149.1.18. $\mathrm{CE}$, aunque parte de la regla general del silencio positivo, incluyó como novedad el criterio del silencio desestimatorio en lo que se refiere a actividades que puedan producir daños al medio ambiente (art. 24.1). Y la reciente STC 70/2018, de 21 de julio, ha declarado contraria a dicho precepto básico y, por tanto, inconstitucional, la previsión de la Ley murciana que atribuía efectos estimatorios al silencio administrativo en materia de licencias ambientales locales.

En este trabajo se describen muy someramente el panorama normativo de las licencias de actividad, las razones en las que se basa la aplicación del silencio negativo a la tramitación de estas (que van más allá de la mera previsión de la Ley general procedimental) y los efectos unificadores que la doctrina del Tribunal Constitucional tiene respecto al régimen del silencio administrativo en las licencias ambientales.

\section{LAS LICENCIAS AMBIENTALES: DE LA REGULACIÓN ÚNICA A LA MÁXIMA HETEROGENEIDAD POR LA AUSENCIA DE NORMATIVA BÁSICA}

El Reglamento de Actividades Molestas, Insalubres, Nocivas y Peligrosas (RAMINP), aprobado por Decreto 2414/1961, de 30 de noviembre, ha tenido una vigencia ciertamente extensa, a pesar de tratarse de una norma ambiental y, por ello, muy vinculada a la evolución técnica y tecnológica.

Como es sabido, la Constitución atribuye la competencia legislativa básica en materia de medio ambiente al Estado, que es quien debería actualizar con carácter general la regulación de las llamadas actividades clasificadas para todas las Comunidades Autónomas, sin perjuicio del posible desarrollo por estas.

Sin embargo, el Estado no ha tenido la voluntad de aprobar una ley de "actividades clasificadas», es decir, reguladora de las licencias de actividad de competencia municipal dirigidas a la protección ambiental, y menos aún unificar con carácter básico el régimen del silencio administrativo de dichas licencias, a pesar de las propuestas en este sentido (García Garro, 2013: 135). Sorprendentemente, el legislador estatal ha derogado el RAMINP (de forma condicionada, eso sí) por la Ley 34/2007, de 15 de noviembre, de calidad del aire y protección de la atmósfera (DD única.1) pero no ha dictado una normativa estatal sustitutoria. Únicamente, en transposición de la normativa comunitaria, las Cortes aprobaron la Ley reguladora de las autorizaciones ambientales integradas, aplicable a las instalaciones cuya actividad incide intensamente en el medio ambiente (Ley 16/2002, de Prevención y Control Integrados de la Contaminación). Pero la pasividad respecto de las licencias de actividades con menor incidencia ambiental ha llevado a la multiplicación de regímenes autonómicos heterogéneos en esta materia (Lozano y Alli, 2018: 275).

De la misma forma, el silencio positivo (bien que con denuncia de mora) del procedimiento de solicitud de estas licencias, regulado en el RAMINP, ha sido sustituido por regímenes procedimentales de licencias de actividad con silencio negativo o positivo, según la Comunidad Autónoma de que se trate, aunque han venido siendo mayoritarias las regulaciones autonómicas que acogen el silencio estimatorio (Fortes, 2011, 192)².

\footnotetext{
2 Sin ánimo de exhaustividad, disponen que el silencio será estimatorio las normativas murciana (art. 64.3 de la Ley 4/2009, de protección ambiental integrada de Murcia, tras la modificación operada por la Ley 2/2017, ya declarado parcialmente inconstitucional), valenciana (art. 60.2 Ley 6/2014, de 25 de julio, de Prevención, Calidad y Control ambiental de Actividades en la Comunitat Valenciana), castellano leonesa (art. 33.4 Decreto legislativo 1/2015, de 12 de noviembre, por el que se aprueba el texto refundido de la Ley de Prevención Ambiental de Castilla y León), andaluza (art. 16.2 Decreto 297/1995, de 19 de diciembre, por el que se aprueba el Reglamento de Calificación Ambiental) o aragonesa (art. 79.2 Ley 11/2014, de 4 de diciembre, de Prevención y Protección Ambiental de Aragón);
} 
En todo caso, las licencias («ambientales» o «de actividad») encuadradas, por la relativa importancia de las actividades a ellas sometidas, a medio camino entre las autorizaciones ambientales integradas (relativas a actividades de elevada incidencia ambiental) y las meras comunicaciones (aplicadas a actividades de escaso efecto ambiental) se crean para proteger el medio ambiente, de forma integrada, frente a los daños derivados del ejercicio de esas actividades.

\section{EL SILENCIO EN LAS AUTORIZACIONES AMBIENTALES DEBE SER NEGATIVO}

\subsection{La paulatina recepción de esta doctrina por el legislador español}

Tradicionalmente se ha venido entendiendo que las autorizaciones constituyen una remoción de obstáculos para el ejercicio de derechos preexistentes ${ }^{3}$. De ahí que una consecuencia lógica de esta naturaleza jurídica fuera el régimen de silencio positivo (cfr., art. 43.2 Ley 30/1992, en su versión original: «Cuando en los procedimientos iniciados en virtud de solicitudes formuladas por los interesados no haya recaído resolución en plazo, se podrán entender estimadas aquéllas en los siguientes supuestos: b) Solicitudes cuya estimación habilitaría al solicitante para el ejercicio de derechos preexistentes, salvo que la estimación tuviera como consecuencia que se transfirieran al solicitante o a terceros facultades relativas al dominio público $o$ al servicio público, en cuyo caso se entenderán desestimadas».)

Sin embargo, algunos autores afirman que el derecho a realizar las actividades condicionadas por licencias ambientales parece que es «otorgado» por la Administración, de forma que la licencia ambiental evoluciona hacia la institución de la concesión, con tintes constitutivos, más que declarativos de la preexistencia del derecho (Betancor, 2014: 1258). Esta visión se condice mejor con el silencio desestimatorio, a la luz de lo señalado en la vieja Ley 30/1992.

En el ordenamiento español, la previsión del silencio negativo tuvo también su parcial plasmación (sectorial) en el 1778/1994, de 5 de agosto, por el que se adecuan a la Ley 30/1992, de 26 de noviembre, de Régimen Jurídico de las Administraciones Públicas y del Procedimiento Administrativo Común, las normas reguladoras de los procedimientos de otorgamiento, modificación y extinción de autorizaciones, que asignó dicho efecto a la falta de resolución en plazo de las solicitudes de autorización en materia de aguas, costas y residuos tóxicos y peligrosos (Anexo, J, núms. 2, 3 y 4).

Con posterioridad, la Ley 16/2002, de 1 de julio, de Prevención y Control Integrados de la Contaminación (hoy sustituida por el RD Legislativo 1/2016, de 16 de diciembre, por el que se aprueba el texto refundido de la Ley) que regula las autorizaciones ambientales integradas, estableció también el silencio desestimatorio de las solicitudes (art. 21.2), de acuerdo con el art. 8 de la Directiva 96/61, que transpone.

Finalmente, la regla del silencio desestimatorio fue recogida, con carácter general, por la Ley básica 39/2015, de 1 de octubre, en su art. 24.1:

«El silencio tendrá efecto desestimatorio en los procedimientos (...) [que] impliquen el ejercicio de actividades que puedan dañar el medio ambiente».

Parece, por tanto, bastante evidente, no solo la conveniencia (Lozano y Alli, 2018: 278), sino la necesidad, de acuerdo con los principios generales del derecho ambiental, de que los procedimientos autorizatorios sustitutorios de las licencias RAMINP se rijan por el silencio negativo o desestimatorio (Pleite, 2017: 2).

\subsection{La jurisprudencia europea: el silencio positivo no asegura el control público ambiental}

Esta exigencia del silencio negativo se recogió tempranamente por la jurisprudencia del Tribunal de Luxemburgo, con referencia a las autorizaciones reguladas por algunas Directivas; la STJCE de 28 de fe-

\footnotetext{
prevén el silencio negativo, entre otras, la normativa vasca (art. 48.3 Ley 20/2009, de 4 de diciembre, de prevención y control ambiental de las actividades), navarra (art. 56.3 Ley Foral 4/2005, de 22 de marzo, de intervención para la protección ambiental), catalana (art. 48.3 Ley 20/2009, de 4 de diciembre, de prevención y control ambiental de las actividades) o riojana (art. 21 c) Ley 6/2017, de 8 de mayo, de Protección del Medio Ambiente de la Comunidad Autónoma de La Rioja), entre otras.

3 Según la definición de Oreste RANELETTI. Entre la doctrina alemana destaca, desde una perspectiva distinta y complementaria, la también tradicional definición de Otto MAYER, según la cual la autorización se configura como un acto administrativo que levanta una prohibición previa, tras la comprobación de que el ejercicio de dicha actividad en el caso concreto no provoca perjuicios para el interés general (LAGUNA, 2006: 113-118).
} 
brero de 1991 (as. 360/87, Comisión c. Italia) condenó a Italia por transponer inadecuadamente la Directiva «aguas subterráneas» (80/68, de 17 de diciembre), en cuanto que preveía una autorización provisional tácita para vertidos en dichas masas de agua. Según el Tribunal, dicha autorización tácita no era compatible con los objetivos de la Directiva, porque la autorización debía concretarse en un acto expreso: la autorización silente no asegura que el control ambiental se haya efectuado (Aguado, 2001: 381 ss.) $)^{4}$. Esta previsión de silencio desestimatorio es aplicable igualmente a las autorizaciones ambientales integradas, cuya normativa de transposición se ajusta hoy de forma correcta al carácter escrito, discrecional y motivado de la resolución, que no puede ser tácita en ningún caso, de acuerdo con la Directiva 96/61.

Con posterioridad, la STJCE de 14 de junio de 2001 (asunto C-230/00) confirmó este criterio respecto de esta y otras Directivas comunitarias ambientales (vertidos, residuos, emisiones, evaluación de impacto): «una autorización tácita no puede ser compatible con las exigencias de las Directivas a que se refiere el presente recurso, puesto que en ellas se establecen mecanismos de autorización previa, en el caso de las Directivas 75/442 [residuos], 76/464 [vertidos], 80/68 [aguas subterráneas] y 84/360 [emisiones a la atmósfera], o bien procedimientos de evaluación anteriores a la concesión de la autorización, en el caso de la Directiva 85/337 [Evaluación de Impacto Ambiental]» (núm. 16). Acogiendo esta doctrina, aunque con una argumentación mucho más extensa, el Tribunal Supremo español ha entendido inaplicable el régimen de silencio positivo a las Evaluaciones de Impacto Ambiental en nuestro ordenamiento, como afirma con claridad la STS de 28 de mayo de 2012, Rec. núm. 991/2009, FFDD $7 .{ }^{\circ}$ y $8 .{ }^{\circ}$ ).

Por tanto, en Derecho comunitario, el carácter escrito y discrecional de las autorizaciones y la necesidad de realizar determinados controles y de tener en consideración informes y alegaciones de Administraciones y de sujetos interesados, impide de todo punto la existencia de un régimen de silencio administrativo positivo.

\subsection{Algunas previsiones de derecho comparado. La Administración no puede abdicar de su responsabilidad ambiental}

También en el Derecho comparado se ha asumido el criterio de la prohibición de silencio positivo en las materias ambientales. El caso más evidente, por conocido, es el relativo al sistema francés. En cierto sentido, se podía reconocer como principio o regla general el silencio negativo o desestimatorio en materia ambiental, ya desde finales de los años sesenta, tal y como estableció la Décision 69-55 L, de 26 de junio de 1969 del Conseil Constitutionnel; de acuerdo con ello, se llegó a afirmar que «en materia de protección de la naturaleza y del medio ambiente, habría que prohibir totalmente toda autorización o derogación tácita: esto es lo que determina el valor de la regla que había creído poder afirmar el Conseil Constitutionnel» (Waline, 1974: 1205), aunque esta regla fue contestada por el Conseil d'État (FAVOREU y PHILIP, 2009: 168 ss) y el propio Conseil Constitutionnel la limitó, al afirmar, años más tarde, que el legislador podría derogarla (Décision 94-352 DC).

El silencio desestimatorio en materia ambiental no está incluido en el listado de excepciones (previsto en el art. L. 231-4 et L. 231-5 del Code des relations entre le public et l'administration) frente al principio de silencio positivo aplicable a las relaciones Administración-administrados, consagrado por la ley de 12 de noviembre de 2013 (Desprairies, 2017:110). Ahora bien, sin perjuicio de ello, la normativa vigente reguladora de la nueva autorización ambiental única ${ }^{5}$ incluye el silencio negativo, sin matices, como regla general en el caso de que la solicitud de autorización ambiental no se resuelva en plazo (art. R181-42) .

4 Cdo. 31: «Por consiguiente, una autorización tácita no puede ser compatible con las exigencias de la Directiva, máxime cuando, como ha señalado la Comisión, semejante autorización no permite la realización de investigaciones previas ni posteriores, ni de controles. De ello se deduce que la legislación nacional no se ha adaptado a la Directiva con precisión y claridad suficientes para satisfacer plenamente la exigencia de seguridad jurídica». Como puede apreciarse, el concepto de autorización «tácita» que utiliza el Tribunal de Justicia y la jurisprudencia o doctrina comparadas (sobre todo, la francesa) responde a lo que en el ordenamiento español se viene calificando como autorización «presunta», habida cuenta de que los actos tácitos en España son aquellos derivados, no de una presunción legal, sino de hechos concluyentes (García-Trevijano, 1986: 161).

5 Introducida por la Ordenanza núm. 2017-80 de 26 de enero de 2017, relativa a la autorización ambiental (en aplicación de la Ley «Macron», de 6 de agosto de 2015 para el crecimiento, la actividad y la igualdad de oportunidades económicas, fusiona los procedimientos de instrucción y de emisión de diversas autorizaciones. Esta Ordenanza y los Decretos del mismo día $2017-81$ et $2017-82$ están codificados en los artículos L. 181-1 et R. 181-1 y siguientes del Code de l'Environnement, dentro del capítulo titulado «Autorización ambiental».

6 «Le silence gardé par le préfet à l'issue des délais prévus par l'article R. 181-41 pour statuer sur la demande d'autorisation environnementale vaut décision implicite de rejet». 
También en Derecho belga se apunta a ello. El Conseil d'État sugiere la inconstitucionalidad de una sistema de control autorizatorio «tácito» en materia de medio ambiente, porque puede suponer la renuncia de las autoridades a ejercer las funciones a ellas confiadas por el art. 23 de la Constitución de ese país en materia ambiental (Avis 25.689, de 1997, VII) ${ }^{7}$. Esta doctrina ha sido reiterada posteriormente en numerosos Avis del mismo Conseil d'État ${ }^{8}$.

\subsection{Justificación del silencio negativo: el papel de los principios de proporcionalidad y de prevención}

\subsubsection{El principio de proporcionalidad: si no hay posibles daños al ambiente (u otra razón imperiosa de interés general), no cabe exigir autorización}

El principio de proporcionalidad impone que las limitaciones o restricciones a la actividad económica sean adecuadas a sus fines, proporcionadas a sus objetivos, de tal forma «que los requisitos [impuestos a dicha actividad privada] sean adecuados para garantizar la realización del objetivo que se persigue y no vayan más allá de lo necesario para conseguir dicho objetivo y que no se puedan sustituir por otras medidas menos restrictivas que permitan obtener el mismo resultado» (art. 15.3 c) Directiva 2006/123, de servicios). Lo señala con claridad esta Directiva: para facilitar el ejercicio de la libertad de establecimiento reconocida en los Tratados (art. 1.1 Directiva), los regímenes de autorización de actividades de servicios solo son legítimos si (entre otros requisitos), «b) están justificados por una razón imperiosa de interés general» (art. 10.2 b)). Y la protección del medio ambiente (o lo que es lo mismo, la evitación de daños) constituye una «razón imperiosa de interés general» (art. 4.8 Directiva), por lo que queda justificado el régimen de autorización previa por razones de protección del medio ambiente (no hay que olvidar que el medio ambiente ya se venía configurando por la jurisprudencia comunitaria como un límite a las libertades comunitarias: García Álvarez, 2012: 348 ss) que exige un control previo de la actividad potencialmente dañosa (Cubero, 2013: 124).

La normativa española mantiene este criterio, lógicamente (Cosculluela, 2016: 111-112), tal como reconoce la Ley 17/2009, de 23 de noviembre, sobre el libre acceso a las actividades de servicios y su ejercicio, cuyo art. 3.3 incluye «la protección del medio ambiente y del entorno urbano» como una «razón imperiosa de interés general» (núm. 11).

En resumen, la evitación de daños relevantes al ambiente se considera una razón imperiosa de interés general que justifica la existencia de la previa autorización o licencia ambiental, aunque no han faltado autores que entienden que esa intervención autorizatoria podría sustituirse por otras técnicas como la comunicación previa o la declaración responsable, también por razones de proporcionalidad (Arana y Granados, 2010).

Y al revés: si los daños potenciales al ambiente no son relevantes, no se justificaría la exigencia de autorización (no existiría esa «razón imperiosa de interés general» justificadora de la intervención administrativa previa) y bastaría con la mera comunicación previa o el control a posteriori, de acuerdo con los criterios de la Directiva en general y con el principio de proporcionalidad en particular: es más respetuosa con el derecho del particular la comunicación previa (actividad libre) que la autorización con silencio positivo (actividad inicialmente prohibida). De hecho, sin negar evidentes diferencias entre comunicación previa y autorización (Núñez, 2001: 94; Laguna, 2006: 95), ya tempranamente se señaló la similitud de efectos sobre el medio ambiente, en la práctica, entre el otorgamiento «tácito» y la comunicación con derecho a veto (Waline, 1974: 1203).

Se ha alegado, en relación con el término «daños al medio ambiente», que se trata de un concepto jurídico tan indeterminado que su utilización afectaría a la seguridad jurídica (Pleite, 2017: 2). Sin embargo, es el legislador autonómico el que debe concretar (por lista o mediante cláusula residual) las actividades capaces de dañar el ambiente y, sobre todo, debe aplicar el correspondiente régimen jurídico (silencio positivo o negativo) según entienda que la actividad en cuestión sea o no ambientalmente inocua.

\footnotetext{
7 «En tout état de cause, en admettant que des travaux soient régulièrement exécutés sans qu'une décision administrative soit expressément prise, le système du " permis tacite " pourrait conduire les autorités à renoncer à exercer la mission qui leur incombe, en vertu de l'article 23 de la Constitution, de garantir la protection d'un environnement sain et s'avère, au surplus, incompatible avec les directives de droit européen».

8 P. ej., Avis 26769, de 1998, IV; Avis 42922/4 du 06-06-2007; Avis 44.884/1/V, de 5-08-2008; Avis 44958/3-1/V du 10-09-2008, etc.
} 


\subsubsection{El principio de prevención: si hay daños posibles al ambiente, el silencio debe ser negativo; así se impide su posible legitimación por pasividad administrativa}

Si el principio de proporcionalidad lleva a exigir autorización solo cuando hay riesgo de daños (relevantes) al medio ambiente, el sentido del silencio en estas autorizaciones debe vincularse con el principio preventivo. No es tanto el supuesto carácter "cuasiconcesional» que algunos atribuyen a las licencias ambientales (Betancor, 2014: 1258), dudoso cuando menos o inexistente (Laguna, 2006: 139 ss), sino el principio general de prevención el que lleva a exigir el silencio administrativo negativo en las autorizaciones ambientales.

En efecto, de acuerdo con el principio de prevención (art. 133 AUE; actual art. 191.2 TFUE), ante aquellas actividades capaces de dañar el ambiente (por los riesgos conocidos vinculados al ejercicio de la actividad) resulta preciso adoptar controles previos que impidan los daños o los hagan, al menos, asumibles. La autorización (licencia) de actividades clasificadas se configura, así, como una técnica característica de la prevención ambiental.

Por eso, las actividades en cuestión no deben realizarse si falta el control previo: de ahí que el silencio tenga que ser, en su caso, desestimatorio, porque el silencio positivo no asegura la realización de los controles previos al inicio de la actividad, como señala la jurisprudencia del TJUE y puede dar lugar a daños, en su caso irreparables, al medio ambiente. En efecto, si el silencio es positivo, podría darse el caso de que la pasividad administrativa en la tramitación de la licencia legalizase una actuación contaminante, dañosa para el ambiente, mediante el otorgamiento tácito de dicha licencia (Amado, 2007: 409 y 413).

En definitiva, parece lógico exigir las autorizaciones con silencio negativo para las actividades que pueden producir daños relevantes al medio ambiente y controlar, sin embargo, mediante comunicaciones previas, las actividades que no pueden producir dichos daños, porque en este caso falta la razón imperiosa de interés general, de acuerdo con el principio de proporcionalidad: resultaría absurdo mantener el régimen de la previa autorización para permitir el ejercicio de la actividad en el caso de falta de pronunciamiento expreso.

De esta forma, si hay daños posibles, debe haber autorización y debe haber silencio negativo; si no hay daños de una cierta trascendencia, no cabe la autorización, y por tanto, tampoco se puede hablar de silencio. No tiene sentido el silencio positivo en actividades potencialmente dañosas al medio ambiente.

\section{LA CONFIRMACIÓN DEL SILENCIO NEGATIVO: LA STC 70/2018, DE 21 DE JULIO Y SUS CONSECUENCIAS PARA EL RÉGIMEN JURÍDICO EN LAS LICENCIAS AMBIENTALES}

La doctrina de la reciente sentencia del Tribunal Constitucional de 21 de julio va a tener importantes consecuencias en el régimen jurídico de las licencias ambientales: por una parte, y no es poco, declara doctrina «básica» en un ámbito en el que el legislador estatal básico «se había escondido». Por otra parte, aplica con claridad el silencio negativo a las licencias ambientales reguladas por la Ley murciana, aunque dicha doctrina, como se verá, es aplicable al resto de las regulaciones autonómicas con un régimen similar; finalmente, ofrece criterios interpretativos de la prohibición de obtención de licencias contra legem, aunque en este caso, como veremos, reconoce la posibilidad de una dualidad de interpretaciones.

\subsection{Desaparición del silencio estimatorio en las licencias ambientales}

En esta materia, la primera consecuencia de la STC 70/2018, además de la anulación del correspondiente precepto de la ley murciana por inconstitucional, es la desaparición del silencio positivo o estimatorio de las denominadas «licencias ambientales» en aquellos ordenamientos autonómicos que lo hayan previsto (Comunidad Valenciana, Castilla y León, etc.).

En efecto, más allá de la anulación operada por la sentencia citada, esta pone de manifiesto cómo la previsión básica de la ley 39/2015, exceptuando de la cláusula general del silencio estimatorio las actividades que puedan dañar al medio ambiente (art. 24.1), conlleva automáticamente la inconstitucionalidad de las leyes autonómicas que dispongan lo contrario.

Para ello, tiene que cuadrar el supuesto de hecho de la norma autonómica en el de la estatal. En algunos casos la coincidencia es evidente, porque los términos se reproducen ad pedem litterae: es el supuesto, en primer lugar, de la ley murciana: como señala la propia STC 70/2018, FJ 10: «En suma, la regla de 
procedimiento común fijada por el Estado establece un régimen general de silencio desestimatorio para los procedimientos iniciados a solicitud del interesado que se refieren al ejercicio de actividades susceptibles de dañar el medio ambiente, ámbito de aplicación que coincide, justamente, con el de la licencia de actividad, que, de acuerdo con la Ley autonómica 4/2009, es un instrumento general de control preventivo de actividades "susceptibles de generar daños sobre el medio ambiente"».

Pero también se ajustan claramente al supuesto de hecho estatal la regulación de la Ley cántabra ${ }^{9}, 0$ la de la Ley de Castilla y León ${ }^{10}$. Es patente, en estos supuestos, la inconstitucionalidad de los regímenes autonómicos que mantienen el silencio positivo.

En otros casos se hace precisa una interpretación finalista de la norma autonómica, que acaba abocando a la misma conclusión. Baste analizar algunas leyes, como la Ley valenciana, que en su parte dispositiva no menciona la trascendencia ambiental de las actividades sometidas a licencia ambiental: simplemente alude a la función de la licencia como condicionante de dichas actividades desde esa perspectiva y a la «clasificación» de las actividades, incluidas en el Anexo II. Sin embargo, la Exposición de Motivos de la Ley diferencia de forma expresa entre licencias y autorizaciones ambientales integradas cuando se refiere a los «supuestos de actividades con una elevada o media incidencia ambiental, que por motivos de protección medioambiental y, por tanto, de interés público, se someten a autorización ambiental integrada o a licencia ambiental» (III), o cuando señala que las actividades sometidas a licencia tienen «menores repercusiones sobre el medio ambiente» que aquellas (IV). Por tanto, las actividades sometidas a licencia lo son por razón de su incidencia ambiental «media», lo que viene a confirmar lo señalado más arriba. Para confirmar la trascendencia ambiental de las licencias, la EM recuerda que dentro del Anexo II se incluye «gran parte de las actividades que la anterior Ley 2/2006 remitía a autorización ambiental integrada». Por tanto, actividades que puedan dañar al medio ambiente (art. 24.1 LPAC) capaces de producir daños al medio ambiente, aunque no tan elevados como las sometidas a AAI.

Algo similar cabe decir de la calificación ambiental andaluza, que se integra como un trámite obligatorio en la licencia correspondiente. Esta técnica viene a actualizar la licencia RAMINP. No se menciona expresamente que las actividades susceptibles de ser calificadas ambientalmente sean las capaces de dañar el medio ambiente, pero no se puede deducir algo distinto a la luz del propio concepto (art. 2.1 Decreto 297/1995, de 19 de diciembre, por el que se aprueba el Reglamento de Calificación Ambiental, que define esta como «el procedimiento mediante el cual se analizan las consecuencias ambientales de la implantación, ampliación, modificación o traslado de las actividades incluidas en el Anexo Tercero de la Ley 7/1994, al objeto de comprobar su adecuación a la normativa ambiental vigente y determinar las medidas correctoras o precautorias necesarias para prevenir o compensar sus posibles efectos negativos sobre el medio ambiente» y que viene a concretar la más genérica previsión del art. 42 de la Ley andaluza 7/2007, de 9 de julio, de Gestión Integrada de la Calidad Ambiental); además, el propio régimen sancionador de la citada Ley 7/2007 confirma la trascendencia ambiental de las actividades sometidas a licencia municipal con calificación ambiental, al calificar como muy grave la realización de la actividad sin dicha calificación ${ }^{11}$ : si no hubiera daños ambientales en juego, no se habría previsto la licencia ni una calificación tan grave de la ausencia de dicho trámite.

Una vez afirmado lo anterior, cabe entrar a valorar si el silencio estimatorio subsiste en aquellos supuestos en los que la norma lo condiciona a la existencia de un previo informe o declaración de impacto positivos: es el caso de la normativa aragonesa. La Ley 11/2014, de 4 de diciembre, de Prevención y Protección Ambiental de Aragón, establece en su art. 79.2:

«Transcurrido el plazo máximo sin haberse notificado la resolución, podrá entenderse estimada la solicitud presentada, siempre que se haya emitido el informe de calificación de la acti-

9 Ley 17/2006, de 11 de diciembre, de control ambiental integrado, cuyo art. 31, relativo al objeto de la «comprobación ambiental», alude a ellas: «1. Las licencias para la realización de actividades o el establecimiento y funcionamiento de instalaciones, así como para su modificación sustancial, que puedan ser causa de molestias, riesgos o daños para las personas, sus bienes o el medio ambiente y no precisen de autorización ambiental integrada ni declaración de impacto ambiental, se otorgarán previa comprobación y evaluación de su incidencia ambiental».

10 Se deduce de la idéntica descripción del supuesto de hecho en el art. 24.1 LPAC y en el art. 25.1 del Texto Refundido de la Ley de Prevención Ambiental de Castilla y León: «Quedan sometidas al régimen de licencia ambiental las actividades o instalaciones susceptibles de ocasionar molestias considerables, de acuerdo con lo establecido reglamentariamente y en la normativa sectorial, de alterar las condiciones de salubridad, de causar daños al medio ambiente (...)».

11 Art. 134.1 de la Ley: «Es infracción muy grave el inicio, la ejecución parcial o total o la modificación sustancial de las actuaciones sometidas por esta ley a calificación ambiental, sin el cumplimiento de dicho requisito». Y las sanciones correspondientes alcanzan los $30.000 €$. 
vidad con carácter favorable o, en su caso, siempre que se hubiera formulado la declaración de impacto ambiental o el informe de impacto ambiental con carácter favorable».

Pues bien, en estos casos parece que hay que entender que el régimen del silencio puede seguir siendo «positivo» sin incurrir por eso en tacha de inconstitucionalidad. La finalidad del silencio negativo del art. 24.1 LPAC es, sin duda alguna, la prevención ambiental, en línea con la doctrina del TJUE y el principio general preventivo. Si los órganos con competencias ambientales se han pronunciado -mediante el dictamen o la DIA - y lo han hecho en el sentido de entender que la actividad cuya licencia se solicita no produce daños ambientales significativos, la licencia puede entenderse otorgada en caso de silencio, porque el control ambiental ya se ha realizado y la actividad se considera inocua (de acuerdo con el dictamen o DIA, la actividad no va a producir daños al medio ambiente). (Amado, 2007: 413 ss).

\subsection{Un avance para la interpretación correcta de la cláusula «contra legem»}

El art. 64.3 de la citada Ley de protección ambiental integrada de Murcia, también enjuiciado en la sentencia del Constitucional, incluye la ya clásica cláusula de salvaguarda del otorgamiento por silencio de licencias «contra legem»: «El otorgamiento por silencio administrativo de la licencia de actividad no concede facultades a su titular en contra del planeamiento urbanístico o de la legislación sectorial aplicable».

Sobre esta cláusula se ha discutido mucho. La STC (FJ 10) presenta dos interpretaciones posibles de esta cláusula, pero no determina cuál es la interpretación correcta: «la solución de este problema gira en torno a dos opciones fundamentales: (i) o bien, la imperatividad de acudir al procedimiento de revisión de oficio para declarar la nulidad del acto presunto que habría sido obtenido por el solicitante; o bien, (ii) la consideración de que tal acto presunto no ha llegado a materializarse, justamente por efecto de la cláusula de salvaguarda que impide adquirir facultades contra legem, bastando, por ello, con que la administración dicte un acto denegatorio expreso fuera de plazo». Únicamente elimina de plano la interpretación aportada por el letrado de la Comunidad Autónoma para defender el texto legal. Pero, al menos, centra el debate posible sobre este tipo de cláusulas.

El problema que se plantea con la cláusula de prohibición de licencias «contra legem» es el siguiente: si se pide una licencia cuya emisión implicaría una infracción del ordenamiento, y la Administración no resuelve en plazo, ¿se genera un acto presunto estimatorio ilegal o no? A la luz del art. 62.1.f) Ley 30/1992 (hoy 47.1 f) LPAC), hay que entender que surge un acto presunto, aunque nulo de pleno derecho. Sin embargo, el Tribunal Supremo afirmó en interés de Ley (STS 28 de enero de 2009) la tesis contraria:

«la regla general es la del silencio positivo, aunque la propia norma contiene la salvedad de que otra norma con rango de Ley o norma de Derecho Comunitario Europeo establezca lo contrario, y esto es lo que sucedía con la vigencia antes, en todo el territorio español, del precepto contenido en el aludido artículo 242.6 del Texto Refundido de la Ley del Suelo de 1992 y ahora con lo dispuesto en el artículo 8.1 b), último párrafo, del Texto Refundido de la Ley de suelo de 2008, y, por consiguiente, conforme a ellos, no pueden entenderse adquiridas por silencio administrativo licencias en contra de la ordenación territorial o urbanística» (FD 5. ${ }^{\circ}$ ).

Eso conlleva que no surge un acto estimatorio presunto. Pero la siguiente pregunta es: ¿qué pasa entonces en estos casos?

Para algunos, la cláusula contra legem conllevaría que, si la solicitud es legal, el silencio sería positivo y que si la solicitud es ilegal, el silencio sería negativo. Por lo tanto, el sentido estimatorio o desestimatorio del silencio dependería, no del procedimiento en cuestión, sino de la adecuación al ordenamiento de lo solicitado. Como señala la propia sentencia (FJ 10), refiriéndose al Letrado de la Comunidad Autónoma, en su opinión, el artículo 64.3 de la citada Ley de protección ambiental integrada «no contiene una sino dos reglas de silencio administrativo», el silencio negativo para «todas las solicitudes que contravengan el planeamiento urbanístico o la legislación sectorial (ambiental, sanitaria, de seguridad, de patrimonio cultural) que resulte aplicable al ejercicio de la actividad solicitada (art. 64.3 párrafo segundo)» y el silencio positivo «solo para las solicitudes conformes con el planeamiento urbanístico y la legislación sectorial (art. 64.3 párrafo primero)». Así lo afirman diversos autores, en referencia a la operatividad de la citada cláusula en materia urbanística (Cantó, 2009: 464 ss; Quintana, 2006: 420), etc.) o, incluso, en las licencias ambientales (Morillo-Velarde, 2006: 474) y parece confirmar la STS de 28 de enero de 2009, tal y como ha entendido la doctrina (Cantó, 2009: 466; Razquin, 2009; Morillo-Velarde, 2006: 474). 
El Tribunal rechaza de todo punto esta interpretación con argumentos contundentes: «no es razonable entender (...) que el único efecto de la expiración del plazo para resolver sea, incluso cuando la regla de procedimiento sea de silencio positivo, permitir al afectado acudir a los tribunales, pues si, en efecto, el solicitante acudiera en tal caso a los órganos del Poder Judicial invocando la regla del párrafo segundo del artículo 64.3 de la Ley de protección ambiental integrada de Murcia, él mismo estaría reconociendo, implícitamente, que su solicitud es contraria a la legislación aplicable, lo que resulta manifiestamente absurdo». Y sigue diciendo: «En realidad, sólo cuando la Administración dicta, fuera de plazo y sin necesidad de acudir al procedimiento de revisión de oficio, el acto expreso denegatorio de la solicitud, el ciudadano afectado se encuentra en la misma posición que determina, por sí sola y de forma directa, la regla de silencio negativo o desestimatorio, pues únicamente en ese momento, puede entender que su solicitud le ha sido denegada y que no tiene más alternativa que acudir a los tribunales» (FJ 10).

De esta forma, el TC margina lo que ha sido la interpretación más generalizada, tanto de la cláusula legal de prohibición de licencias contra legem, en general, como de la doctrina jurisprudencial mayoritaria cristalizada en la STS de 28 de enero de 2009.

De acuerdo con lo anterior, la única opción ante el transcurso del plazo para conceder la licencia sin que se haya pronunciado la Administración, existiendo prohibición de licencias contra legem es: o estamos ante un silencio positivo que genera un acto nulo de pleno derecho (art. $47.1 \mathrm{f}$ ) LPAC), susceptible, por tanto, de revisión de oficio aunque dotado de ejecutividad inmediata, o estamos ante la denominada «inexistencia», esto es, ante la ausencia de un acto o incluso de una ficción legal de acto, o lo que es lo mismo, ante una prolongación del procedimiento que solo puede terminar de forma expresa. El TC, desde una perspectiva constitucional, no apuesta por una u otra interpretación, aunque tras la lectura del Fundamento Jurídico, parece reconocerse una mayor dificultad para asumir la interpretación del «acto inexistente» ${ }^{12}$.

Esta doctrina impide entender que la doctrina legal (según la cual no hay silencio positivo contra legem) se interprete como una dualidad de posibilidades de silencio estimatorio o desestimatorio en función del ajuste a la ley de la solicitud. Por lo tanto, confirma que la inexistencia de silencio positivo contra legem no conlleva silencio negativo, sino algo distinto, no encuadrable en las categorías legales del acto administrativo...: pendencia o lo que es lo mismo, «inexistencia» del acto.

La inseguridad jurídica derivada de la doctrina de la STS de 28 de enero de 2009, así como su pobreza argumental, añadidas a la ausencia de un pronunciamiento positivo del Constitucional al respecto, constituyen el caldo de cultivo de la reciente «conversión» del silencio positivo en negativo en las licencias urbanísticas «mayores», que se encuentra plasmada en el vigente art. 11.4 RD Legislativo 7/2015, de 30 de octubre, por el que se aprueba el texto refundido de la Ley de Suelo y Rehabilitación Urbana (TRLS) ${ }^{13}$. La STC 70/2018 ha dado un pequeño paso adelante en la correcta interpretación de la cláusula prohibitiva de licencias contra legem, pero no termina de desbrozar todo el territorio ocupado por doctrinas confusas generadoras de inseguridad jurídica.

\section{CONCLUSIONES}

Desde la entrada en vigor de la Ley 39/2015, de Procedimiento Administrativo Común, cuyo art. 24 impone el silencio desestimatorio en aquellos procedimientos que se refieran a actividades que puedan producir daños al medio ambiente, hay que entender que no tiene cabida ya en el derecho (autonómico) español el silencio positivo en la emisión de las licencias ambientales o «de actividades clasificadas» de competencia municipal, salvo que se vincule a un dictamen o actuación previa que suprima, de hecho, el riesgo ambiental. Esta conclusión viene confirmada por la reciente STC 70/2018, de 21 de julio.

\footnotetext{
12 «En efecto, incluso si se asume la interpretación que excluye la existencia de un acto estimatorio presunto que haya de ser declarado nulo, no resulta jurídicamente defendible que una regla de procedimiento que asigna un efecto estimatorio del silencio (complementada por una prohibición de adquirir facultades contrarias al ordenamiento jurídico) sea completamente equivalente, en todos sus efectos jurídicos, al establecimiento directo de una regla procedimental de silencio negativo o desestimatorio». «Por todo ello, sin necesidad de determinar qué interpretación haya de darse, desde la óptica de la legalidad ordinaria, al párrafo segundo del artículo 64.3 de la Ley de protección ambiental integrada de Murcia, sólo cabe concluir que, incluso admitiendo que tal precepto exima de acudir al procedimiento de revisión de oficio, habilitando a la Administración competente a dictar un acto expreso denegatorio fuera de plazo, tal circunstancia no hace desaparecer la contradicción normativa (...)»;

13 Sobre la constitucionalidad de este precepto (por motivos competenciales), véanse las SSTC 143/2017, de 14 de diciembre, y 75/2018, de 5 de julio.
} 
La misma sentencia desecha la interpretación de la tradicional cláusula de prohibición de obtención de licencias contra legem como habilitadora de silencio negativo, por conducir al absurdo. La sentencia no incide expresamente en la discrepancia doctrinal entre la tesis de las licencias nulas de pleno derecho (cfr., art. $47.1 \mathrm{~g}$ ) LPAC) y la de las licencias «inexistentes», derivadas ambas de la falta de respuesta administrativa en plazo ante una solicitud ilegal, aunque podría deducirse de la redacción una cierta preferencia por la primera de las tesis citadas.

\section{REFERENCIAS BIBLIOGRÁFICAS}

AGUADO I CUDOLÀ, V. (2001): Silencio administrativo e inactividad. Límites y técnicas alternativas. Madrid: Marcial Pons.

AMADO GOMES, C. (2007): Risco e modificaçao do acto autorizativo concretizador de deveres de protecçao do ambiente. Lisboa: Faculdade de Direito da Universidade de Lisboa.

ARANA GARCÍA, E. y GRANADOS RODRÍGUEZ, J. F. (2010): "La desaparición de las licencias en las actividades clasificadas incluidas en el ámbito de la Directiva de Servicios: el supuesto particular de la legislación ambiental andaluza", en Revista General de Derecho Administrativo, núm. 25.

BETANCOR RODRÍGUEZ, A. (2014): Derecho Ambiental. Madrid: La Ley.

CANTÓ LÓPEZ, T. (2009): "La inaplicación del silencio positivo como vía para la obtención de licencias urbanísticas contra legem (a propósito de la Sentencia del Tribunal Supremo de 28 de enero de 2009)", en Revista Aragonesa de Derecho Administrativo, núm. 34, págs. 449-480.

COSCULLUELA MONTANER, L. (2016): "El impacto del derecho de la UE en la regulación española de la intervención administrativa en la actividad económica”, en Revista de Administración Pública, núm. 200, págs. 103-120. DOI: https://doi.org/10.18042/cepc/rap.200.06.

CUBERO MARCOS, J. I. (2013): La Comunicación Previa, la Declaración Responsable y el Procedimiento Administrativo: Especial referencia al Establecimiento de actividades y a la Prestación de Servicios. Cizur Menor: Thomson Reuters Aranzadi.

DESPRAIRIES, A. (2016): "Le silence positif de l'administration en droit français: Étude sous le prisme de la réforme du 12 novembre 2013", en Administración \& Cidadanía, vol. 11, núm. 1, págs. 99-116.

FAVOREU, L. y PHILIP, L. (2009): Les grandes décisions du Conseil constitutionnel, 15. a éd. Paris: Dalloz.

FORTES MARTÍN, A. (2011): "Silencio administrativo y constitución de empresas, instalación de industrias y apertura de establecimientos", en PAREJO ALFONSO, L. (dir.): El silencio en la actividad de la Administración Pública, págs. 149-200. Valencia: Tirant lo Blanch.

GARCÍA ÁlVAREZ, G. (2012): "La incidencia de la Directiva Servicios en el Derecho Ambiental", en AGUADO I CUDOLÀ, V. y NOGUERA DE LA MUELA, B. (dirs.): El impacto de la Directiva de Servicios en las Administraciones Públicas: aspectos generales y sectoriales, págs. 348 y ss. Barcelona: Atelier.

GARCÍA GARRO, M. A. (2013): Impacto de la Directiva de Servicios en las Licencias Urbanísticas y de Actividades. Cizur Menor: Thomson Reuters Aranzadi.

GARCÍA-TREVIJANO, J. A. (1986): Los actos administrativos. Madrid: Civitas.

LAGUNA DE PAZ, J. C. (2006): La autorización administrativa. Madrid: Civitas.

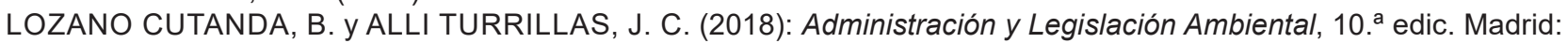
Dykinson.

MORILLO-VELARDE PÉREZ, J. I. (2006): “Licencias ambientales y silencio administrativo”, en QUINTANA LÓPEZ, T. (coord.): El silencio administrativo. Urbanismo y Medio Ambiente, págs. 433-478. Valencia: Tirant lo Blanch.

NÚÑEZ LOZANO, M. C. (2001): Las actividades comunicadas a la Administración. La potestad administrativa de veto sujeta a plazo. Madrid: Marcial Pons.

PLEITE GUADAMILLAS, F. (2017): "En el silencio administrativo no está la respuesta”, en Actualidad Administrativa, núm. 7, págs. 1-3.

QUINTANA LÓPEZ, T. (2006): “El silencio de la administración en el derecho urbanístico”, en QUINTANA LÓPEZ, T. (coord.): El silencio administrativo. Urbanismo y Medio Ambiente, págs. 373-432. Valencia: Tirant lo Blanch.

RAZQUIN LIZÁRRAGA, J. A. (2009): "Silencio administrativo y urbanismo: imposibilidad de adquirir licencias urbanísticas por silencio positivo contra legem”, en Revista Aranzadi Doctrinal, núm. 5, págs. 49-59.

WALINE, M. (1974): "Recensión al libro de J. Malafosse, Le Droit à la nature, Montchrestien, Paris 1973", en Revue de Droit Public, págs. 101-106. 